 \\ STHE UNIVERSITY OF MISSOURI
}

\section{G) ENGINEERING REPRINT SERIES}

Reprint Number 30

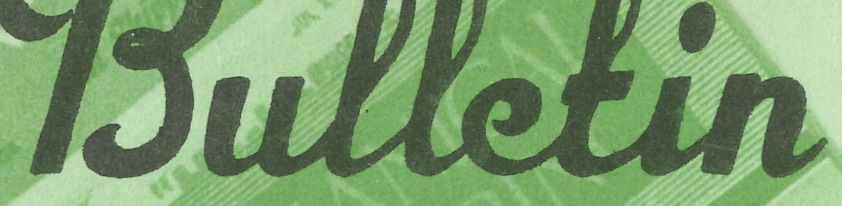

Engineering Experiment Station

Columbia, Missouri

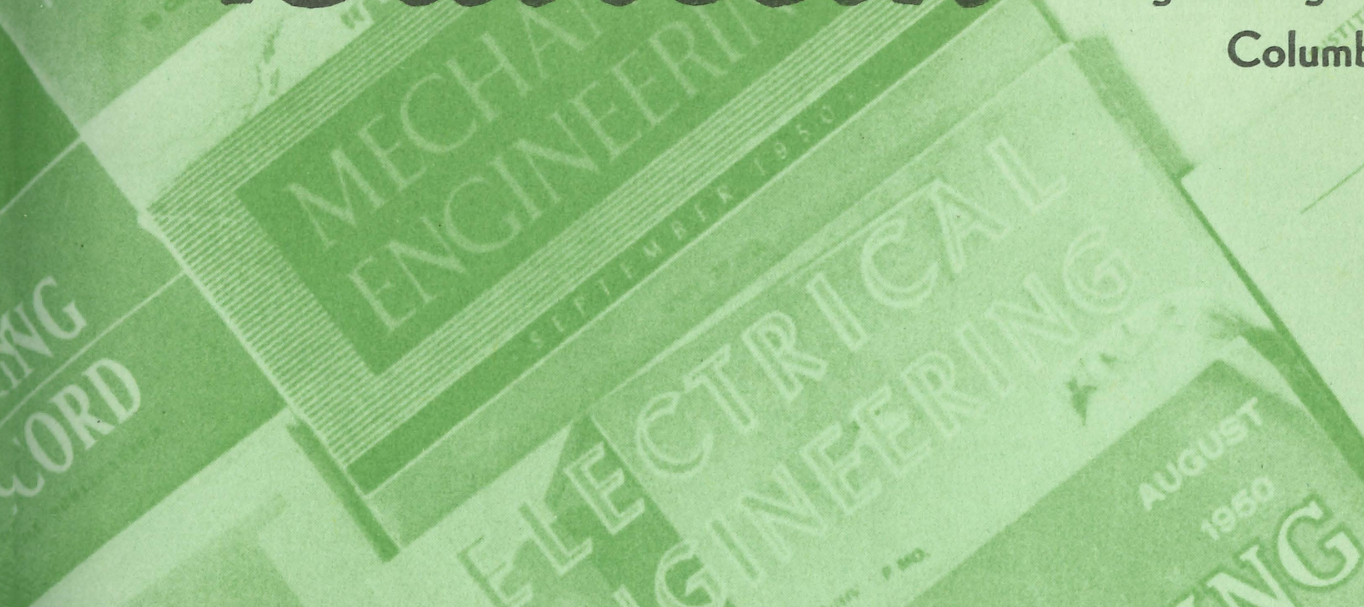

THE INFLUENCE OF SHANK AREA ON THE TENSILE IMPACT STRENGTH OF BOLTS

( $)$ John Love, Jr.

(3) General Electric Company

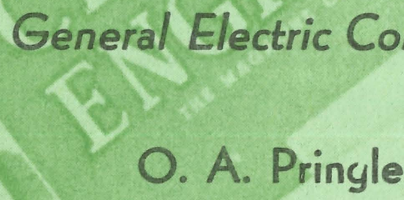

151 Associate Professor of Mechanical Engineering

(9) Transactions of the American Society of Mech

Volume 78, Page 1489, October, 1956. 


\section{COLLEGE OF ENGINEERING \\ THE ENGINEERING EXPERIMENT STATION}

The Engineering Experiment Station was organized in 1909 as a part of the College of Engineering. The staff of the Station includes all members of the Faculty of the College of Engineering, together with Research Assistants supported by the Station Funds.

The Station is primarily an engineering research institution engaged in the investigation of fundamental engineering problems of general interest, in the improvement of engineering design, and in the development of new industrial processes.

The Station desires particularly to co-operate with industries of Missouri in the solution of such problems. For this purpose, there is available not only the special equipment belonging to the Station but all of the equipment and facilities of the College of Engineering not in immediate use for class instruction.

Inquiries regarding these matters should be addressed to

The Director,

Engineering Experiment Station

University of Missouri

Columbia, Missouri

\section{THE UNIVERSITY OF MISSOURI BULLETIN}

VOL. 58 , NO. 28

ENGINEERING REPRINT SERIES, NUMBER 30

Published by the University of Missouri at Room 102, Building T-3, Columbia, Missouri. Entered as second-class matter, January 2, 1914, at post office at Columbia, Missouri, under Act of Congress of August 24, 1912. Issued four times monthly October through May, three times monthly June through September. 


\title{
The Influence of Shank Area on the Tensile Impact Strength of Bolts
}

\author{
By JOHN LOVE, JR., ${ }^{1}$ AND O. A. PRINGLE ${ }^{2}$
}

The effect of reduction of shank cross-sectional area on the tensile impact strength of $5 / 16,3 / 8$, and $7 / 16$-in. steel bolts was investigated experimentally. Low-carbon $3 / 8=$ in. bolts with rolled threads absorbed maximum impact energy when the ratio of shank area to thread-root area was equal to 1.23. Heat-treated medium-carbon $3 / 8$-in. bolts absorbed maximum impact energy when the ratio of shank area to thread-root area was equal to 1.17 for shanks reduced by drilling or $\mathbf{1 . 1 2}$ for shanks reduced by turning. Results for other sizes were similar. It was concluded that for maximum energy absorption the shank area should approximately equal the mean or tensile-stress area of the threads, with minor corrections to compensate for work hardening due to thread rolling or surface oxidation resulting from heat-treatment.

\section{INTRODUCTION}

I $\mathrm{N}$ order to withstand impact loads it is often more important that a machine element be capable of absorbing a given amount of strain energy rather than merely resisting a certain applied force, and for this reason the impact strength of a part is frequently measured by the energy required to produce fracture under impact. It has been pointed out many times that the impact strength of a bolt or similar threaded fastener may be increased by reducing the cross-sectional area of its shank (1 to 4$).^{3}$

In a conventional bolt loaded in tension the stress in the shank is less than the stress in the threaded section, because the shank cross-sectional area is greater than the cross-sectional area at the threads. A reduction in shank area would increase the shank stress, the shank elongation, and the total strain energy absorbed by the bolt. Maximum impact strength should be obtained with the bolt proportioned for equal stresses in the shank and threaded section. Further reduction in shank area would then decrease the impact resistance of the bolt. Therefore the ideal bolt for shock-loading would seem to be one of uniform strength throughout. In attempting to design such a threaded part, past practice has been to reduce the shank area to a value equal to or slightly less than the thread-root area. A shank area equal to 0.9 times the root area has been frequently recommended. This practice was based on two assumptions, i.e., (a) that the threadroot area was a sufficiently accurate measure of the static strength of the threaded section; and $(b)$ that stress concentration at the root of the threads weakened the threaded section during impact. Lately it has become customary to use the so-called mean

${ }^{1}$ Supervisor, Requisition Engineering, Distribution Assemblies Department, General Electric Company, Cincinnati, Ohio. Assoc. Mem. ASME.

${ }^{2}$ Assistant Professor of Mechanical Engineering, University of Missouri, Columbia, Mo. Assoc. Mem. ASME.

${ }^{3}$ Numbers in parentheses refer to Bibliography at end of paper.

Contributed by the Machine Design Division and presented at a joint session with the Metals Engineering Division at the Diamond Jubilee Annual Meeting, Chicago, Ill., November 13-18, 1955, of The American Society of Mechanical Engineers.

Note: Statements and opinions advanced in papers are to be understood as individual expressions of their authors and not those of the Society. Manuscript received at ASME Headquarters, August 5, 1955. Paper No. 55-A-77. or tensile-stress area as a more accurate measure of the static strength of the threaded section. This is a circular area computed from the mean of the pitch and minor diameters, and is a convenient approximation to the true area of a cross section through the threads. It would seem reasonable in the future to correlate recommended shank areas with stress areas rather than root areas. However, the magnitude of the stress-concentration effect in the threads during impact and the extent to which such an effect should be considered in proportioning the shank for maximum impact strength have been uncertain up to the present time. Thus, although it is well known that the impact strength of a bolt may be increased by reducing its shank, there is no conclusive evidence to show exactly what the size of the reduced shank should be.

Considerable increase in fatigue strength of bolts has been obtained by reducing the shank area $(4,5)$. However, the proportioning of a bolt for single impact by the use of data from fatigue tests or even repeated impact tests may be misleading, since the purpose served by the reduced shank may not be the same in the two cases. In fatigue, the reduced shank may relieve stress concentration at the last thread; also the increased bolt elasticity in comparison with the elasticity of the clamped parts may result in a smaller fraction of the repeated external load being transferred to the bolt. The effect of notches under fatigue conditions is not necessarily the same as under impact conditions. In the case of fatigue, the notch effect definitely and greatly reduces the endurance limit; therefore the area of the smooth shank can be reduced by a large amount without becoming weaker than the threaded section. In the case of impact, the primary effect of notches may be to promote the transition from the ductile to the brittle type of fracture; however, the brittle ultimate strength may not be substantially lower than the ductile ultimate strength.

The transition from ductile to brittle-type fracture is a factor of importance to be considered in any situation involving impact. This phenomenon is exhibited by several metals, including the ferritic steels, which normally behave in a ductile manner, but which may be made to fracture in a brittle fashion with greatly reduced energy absorption under certain conditions. The most important conditions which tend to bring about this transition are low temperatures, high strain rates, and triaxiality of stresses due to notches $(6,7)$. The Charpy impact specimen is an example of a notch effect severe enough to raise the transition temperature of certain steels into the range of room temperatures. However, the transition temperatures of notched tensile impact specimens tested in pendulum-type machines have usually been well below room temperature. In specifying bolt proportions for maximum impact strength, a distinction should be made as to the type of fracture expected, since optimum bolt proportions for ductile behavior might not prove suitable for brittle behavior.

Although the energy required to produce fracture is often used as a measure of impact strength, the properties of elastic limit and ultimate strength under impact must also be given due consideration. These properties are usually higher than their corresponding static values (8). It would be desirable for a bolt to absorb the energy of an impact load without the stress exceeding the elastic limit; consequently, its elastic limit and elastic resili- 
ence should be high. On the other hand, in applications where actual fracture from an unduly high shock load would have serious consequences, the energy required for rupture would have great practical significance. In any event, reducing the shank area would increase both the elastic resilience and the energy required for rupture.

Experimental investigations of bolted joints or threaded specimens under tensile impact loads have not been numerous. Of historical interest are Sweet's drop tests on several $1{ }^{1 /}{ }_{4}$-in. wrought-iron bolts with shanks reduced to the thread-root area (2). Whittemore, Nusbaum, and Seaquist made comparative static and tensile impact tests on threaded specimens of various sizes, materials, and thread forms, and also discussed the results of several other investigations (9). Moore reported the results of some impact tests on National Fine and Aero threads (10). Forkois, Conrad, and Vigness made shock tests on low-carbon steel bolts with full shanks and shanks reduced to the threadroot area (11).

In summary, there has been much uncertainty regarding the exact value of shank area which should be specified to enable a bolt to absorb the maximum possible amount of impact energy. Reducing the shank area to equal to, or slightly less than, the thread-root area has effected improvement in energy absorption in some instances, but all of the potential improvement may not have been realized. The purpose of the investigation described in this paper was to obtain specific experimental data concerning the effect of shank area on the room-temperature impact strength of some common bolt types, and if possible to determine optimum shank areas corresponding to maximum impact-energy absorption.

\section{ExPERIMENTAL EquipMent}

The bolts tested were $5 / 16$-in- $18,3 / 8$-in- 16 , and $7 / 16^{-i n}-14$ UNC-2A $\times 3$-in. hexagon head-cap screws used with regular and heavy semifinished hexagon nuts. Also tested were $3 / 8$-in-24 UNF-2A $\times 3$-in. hexagon head-cap screws used with finished hexagon thick nuts. All items conformed to ASA B1.1-1949 and ASA B18.2-1952. These sizes were best suited to the capacity of the testing machine available. They were purchased in two materials, namely, 1018 steel, cold-headed with rolled threads; and 1038 steel, quenched and tempered to an average tensile strength of 130,000 psi. For the sake of brevity, the 1018 cold-headed bolts with rolled threads will subsequently be referred to as cold-forged bolts. The 1038 bolts were also coldheaded with rolled threads; however, work-hardeaing effects had been removed by the heat-treatment. The material of the nuts was 1108 steel. Dimensions of a random sample of the bolts were measured to verify that they were within standard tolerances. Average measured values were used in subsequent calculations, although differences between these and nominal dimensions were small. [A typical cap screw and nut as purchased are shown in Fig. 11(A).]

In the course of the investigation it became desirable to determine the effect of variables such as work hardening and heattreatment by preparing some of the specimens in the following material conditions, in addition to the as-purchased conditions: 1018 bolts strain recrystallized at $1225-1250 \mathrm{~F}, 1018$ bolts fully annealed from 1650-1675 F, and 1038 bolts fully annealed from 1550-1575 F.

As would be expected, there was considerable scatter in much of the impact data that were obtained. To secure reasonably reliable results, it was necessary to test many bolts. The number of specimens used to obtain some of the results may be noted by inspecting the appropriate curves, on which each plotted point represents a fractured bolt, Similar quantities of bolts were used in cases where the results are stated but no curves are shown. A total of 1215 bolts was tested.

Reduction of a bolt-shank area was accomplished by either drilling an axial hole through the shank, or by turning down the shank outside diameter. In either case the bolt was held in a standard collet in an engine lathe during the machining operation. Fig. 11(B) shows a drilled bolt which was sectioned to show the location of the hole. Fig. 11(C) shows a typical bolt with a shank reduced by turning.

The bolts were held in the testing machine by the fixture shown diagrammatically in Fig. 1. The two blocks of the fixture acted as the clamped parts of the bolted joint. Identical procedures were used in cleaning, lubricating, assembling, and tightening each bolt in the fixture in order to obtain consistent values of coefficient of friction. In some of the tests bolt elongations were measured with a micrometer, in which case both ends of the bolt were ground flat and parallel. The striking surfaces of the fixture were positioned so that the shock load on the bolt was axial. Fig. 2 shows the fixture installed in the pendulum of the testing machine.

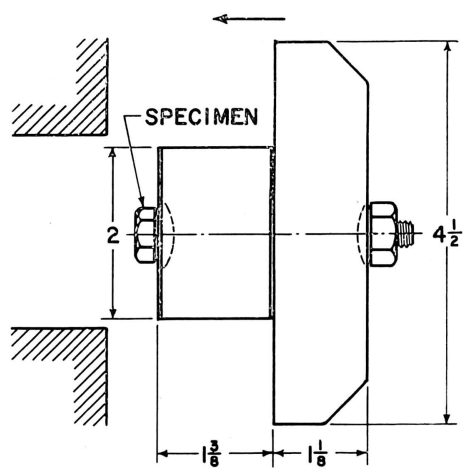

Fig. 1 Diagram of Specimen LOAD FiXTURe
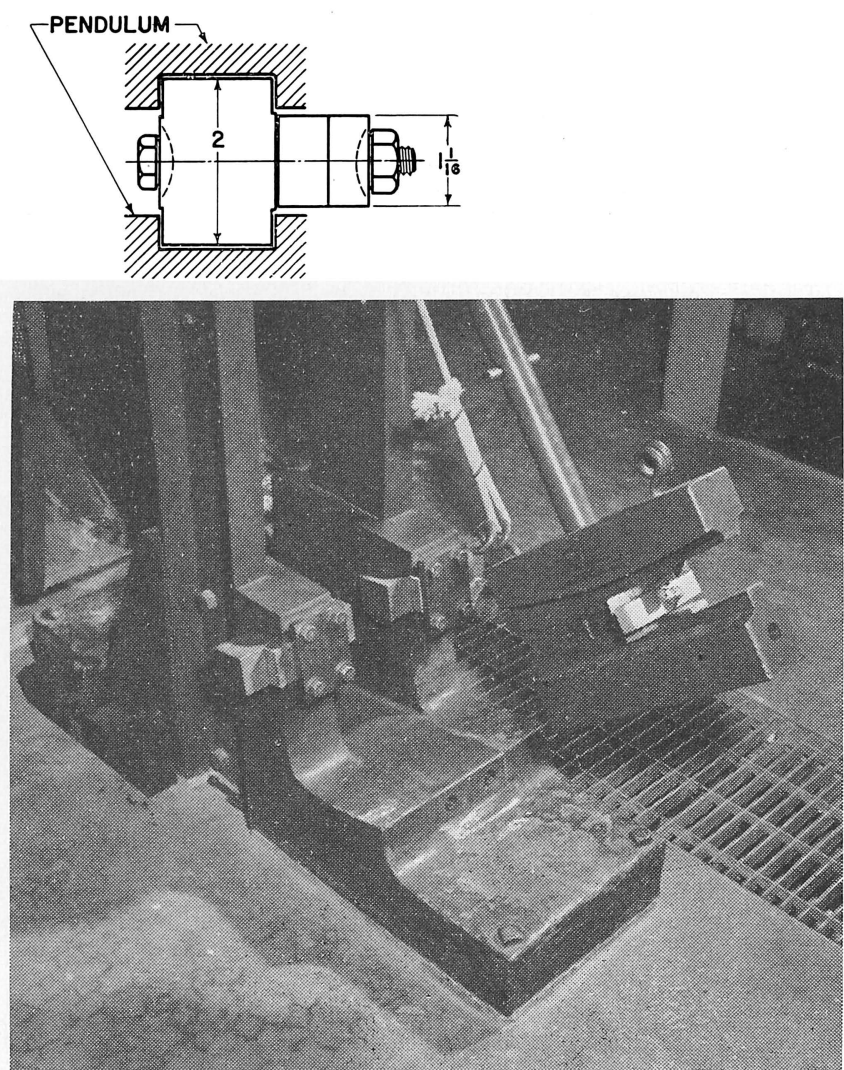

Fig. 2 Specimen Load Fixture Installed in Testing Machine 
The testing machine was a Tinius Olsen pendulum-type universal impact testing machine with a capacity of $348 \mathrm{ft}-\mathrm{lb}$ and a striking velocity of $16.4 \mathrm{fps}$. When the pendulum was dropped, the two blocks of the fixture were pulled apart, thus fracturing the bolt. The energy absorbed during fracture was recorded from the backswing of the pendulum, and could be read to the nearest ft-lb. All tests were made at room temperature.

\section{Test Procedure and Results}

A number of bolts were tested in a preliminary series in order to check the functioning of the testing machine and fixture. During the first tests regular semifinished nuts were used with the UNC bolts; however, failure occasionally occurred by stripping the threads of the nut. Heavy semifinished nuts were substituted and used for the remainder of the tests. No failure of the heavy nuts occurred.

It was desired to tighten the bolts in the fixture to simulate an actual bolted joint; therefore a series of tests was made to determine the effect, if any, of tightening torque on the impact strength of the joint. The $3 / 8$-in. UNC bolts with full shanks were used in as-purchased, strain-recrystallized, and annealed conditions. Various tightening torques were applied, ranging in value from zero to those which caused failure during tightening. After tightening a bolt, its elongation was measured, and the impact strength of the joint determined. Test results are shown in Fig. 3 for two of the material conditions. The resemblance of the elongation curves to stress-strain diagrams indicated that fairly consistent values of coefficient of friction had been obtained during tightening, and it was assumed that the straightline portions of the elongation curves corresponded to initial tightening stresses below the elastic limit. For all materials the scatter band of impact energy appeared to be independent of tightening torque as long as the tightening stress was less than the elastic limit. However, there was a definite decrease in impact strength for tightening stresses above the elastic limit. This drop in impact strength at high tightening stresses is well illustrated by the data for the 1018 strain-recrystallized bolts of Fig. 3 , and it can be seen by comparing the energy and elongation curves that the drop begins when the tightening stress exceeds the elastic limit. The results obtained from the other material conditions were similar, with the possible exception of those for the 1018 cold-forged bolts. As shown in Fig. 3, there was very little reduction in impact strength noticeable for these bolts at tightening stresses above the elastic limit. Probably a very slight reduction in impact strength was concealed by the scatter in the data.

Since impact strength was independent of tightening torque for initial stresses below the elastic limit, conservative values of tightening torque were selected and used in the subsequent tests. Minor variations in coefficient of friction during tightening then had no effect on the impact strength.

The tests to determine the effect of shank area on the energy required for fracture were begun. At first, the tests were made on bolts in the as-purchased conditions; later bolts in the strainrecrystallized and annealed states were tested to assist in explaining the results. Various shank areas were obtained by drilling or turning down the shanks. The bolts were tightened in the fixture and tested to determine the impact energy required for fracture. Typical results are shown in Figs. 4 to 9 , in which the impact strength of each bolt is plotted against the ratio of its shank area to its thread-root area. Bolts with full shanks plot at the extreme right end of each curve. For the curves shown, the length of the reduced section of shank was $1^{5} / 8$ in. for the drilled bolts and $1 \mathrm{in}$. for the turned bolts. The shorter reduced length of the turned bolts was necessary because some of the original shank length was required to support the bolts in the

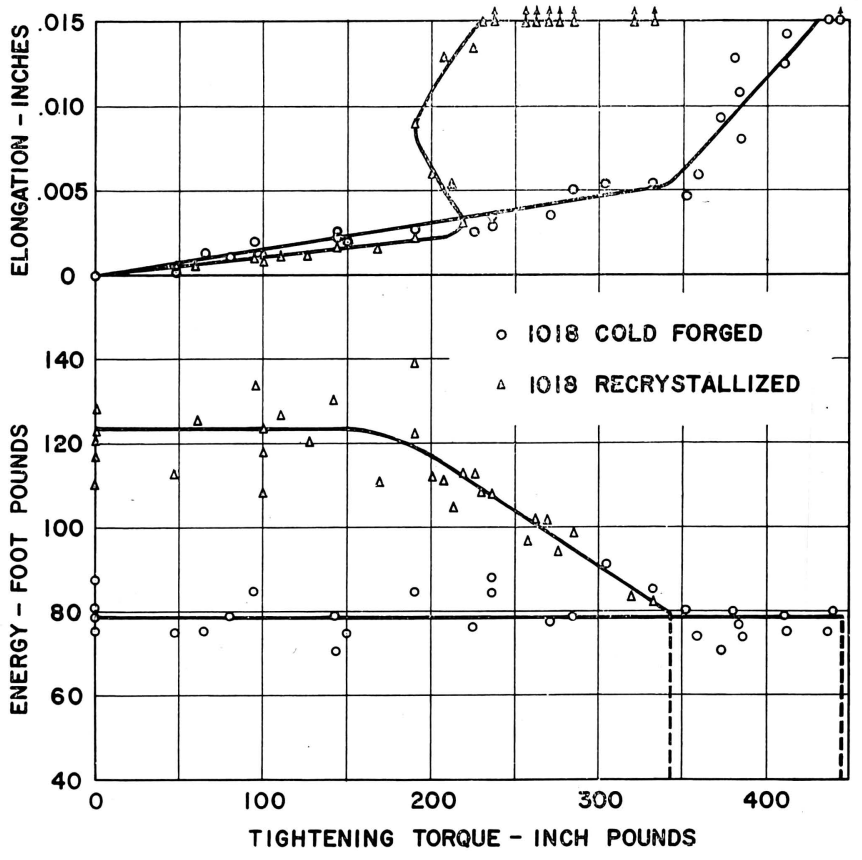

Fig. 3 Effect of Tightening Torque on Bolt Elongation and IMPACT STRENGTH

collet during machining. The length of threaded section exposed under the nut was $1 / 2$ in.

The results show that there was an optimum shank area for each bolt material, and that large increases in energy absorption were obtained by reducing shank areas to these optimum values. Furthermore, the optimum ratios were considerably removed from the ratios of 0.9 or 1.0 which have been recommended in the past. Table 1 lists the optimum ratios for all of the bolts tested in the as-purchased material condition.

TABLE 1 OPTIMUM RATIOS OF SHANK TO ROOT AREA AND SHANK TO STRESS AREA

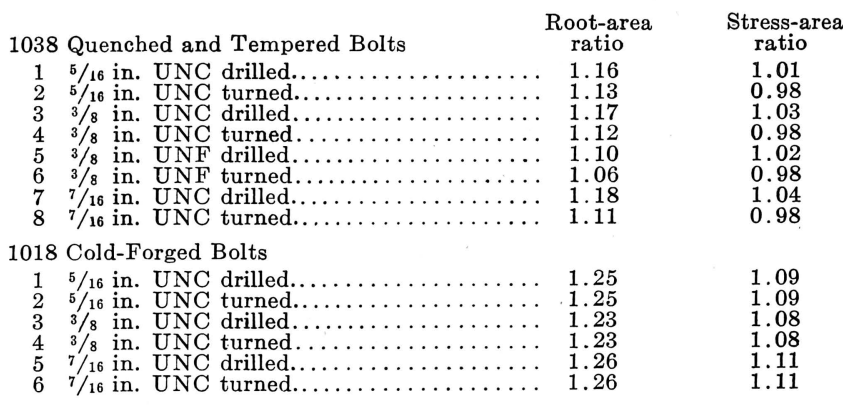

The results presented in Table 1 may be summarized as follows: The optimum shank areas for the 1038 heat-treated bolts were slightly greater than the stress areas if the shanks were reduced by drilling or slightly less than the stress areas if the shanks were reduced by turning; the optimum shank areas for the 1018 cold-forged bolts were all considerably greater than the stress areas, and the same values were obtained regardless of whether the shanks had been reduced by drilling or turning.

The symbols used as plotted points in Figs. 4 to 9 distinguish between shank fractures and thread fractures. When the shankto-root-area ratio was less than the optimum ratio, fracture usually occurred in the shank. When the shank-to-root-area ratio was greater than the optimum ratio, fracture usually occurred in the threads. Thus a bolt with the optimum shank area had a 


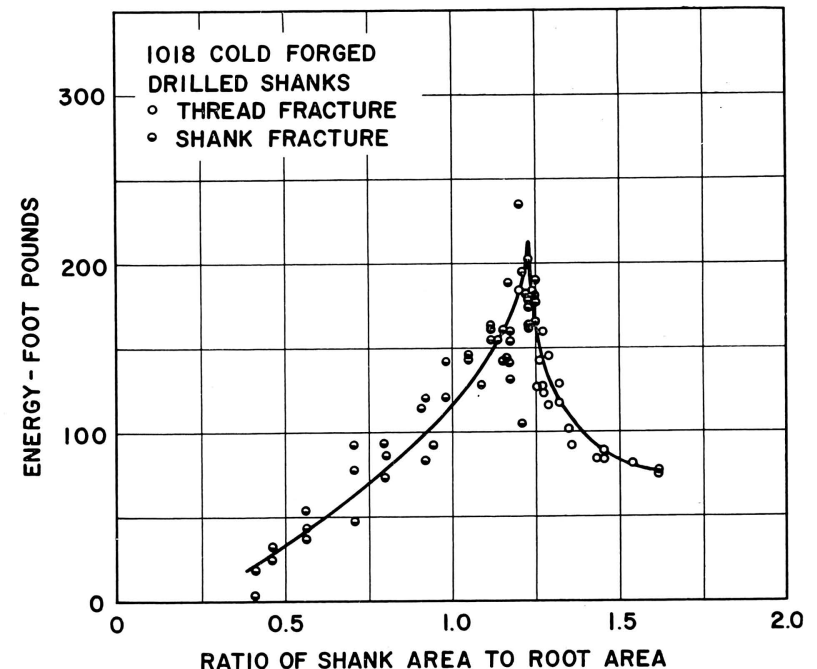

Fig. 4 Effect of Reducing Shank Area by Drilling, 1018 3/8-In. UNC Cold-Forged Bolts

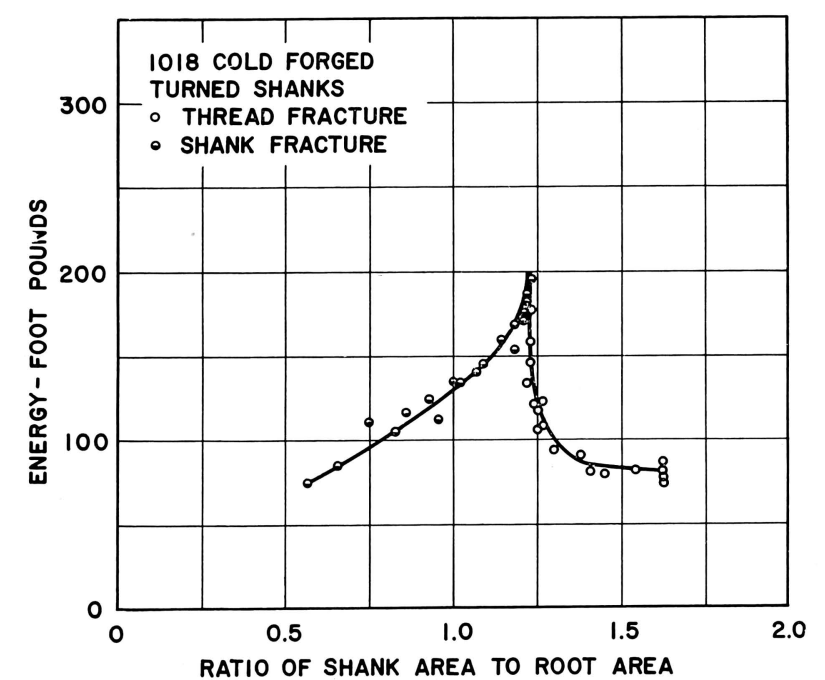

Fig. 5 Effect of Reducing Shank Area by Turning, 1018 3/8-In. UNC COLD-Forged Bolts

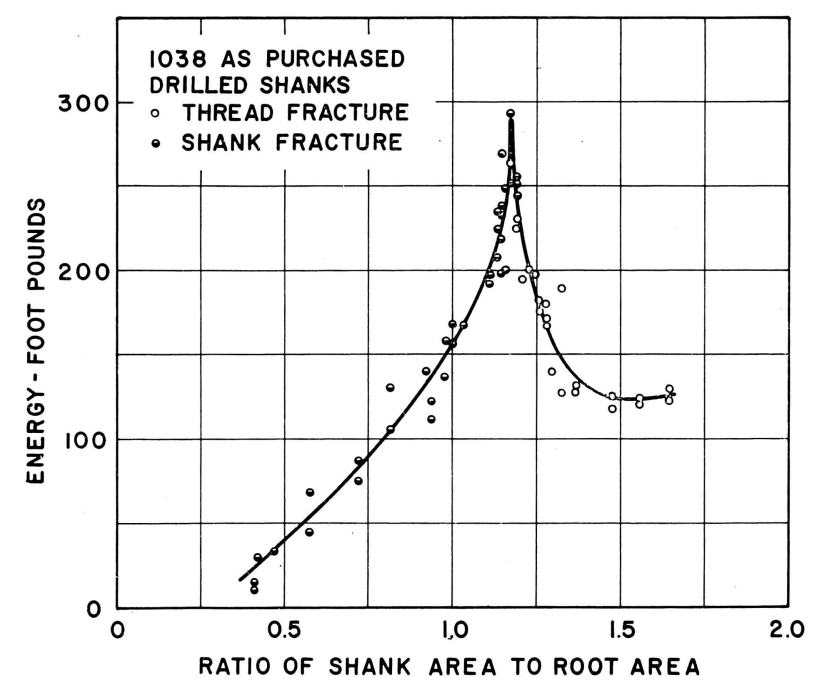

Fig. 6 Effect of Reducing Shank Area by Drilling, 1038 3/8-In. UNC QUENCHED-AND-TEMPERED BOLTS

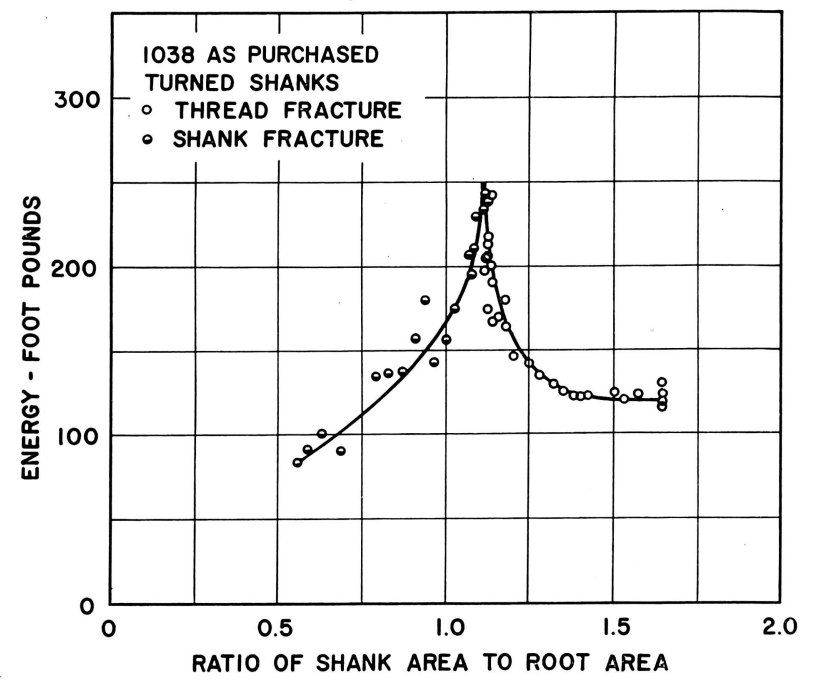

Fig. 7 Effect of Reducing Shank Area by Turning, $1038^{3 / 8}$-In UNC Quenched-AND-Tempered BoLts

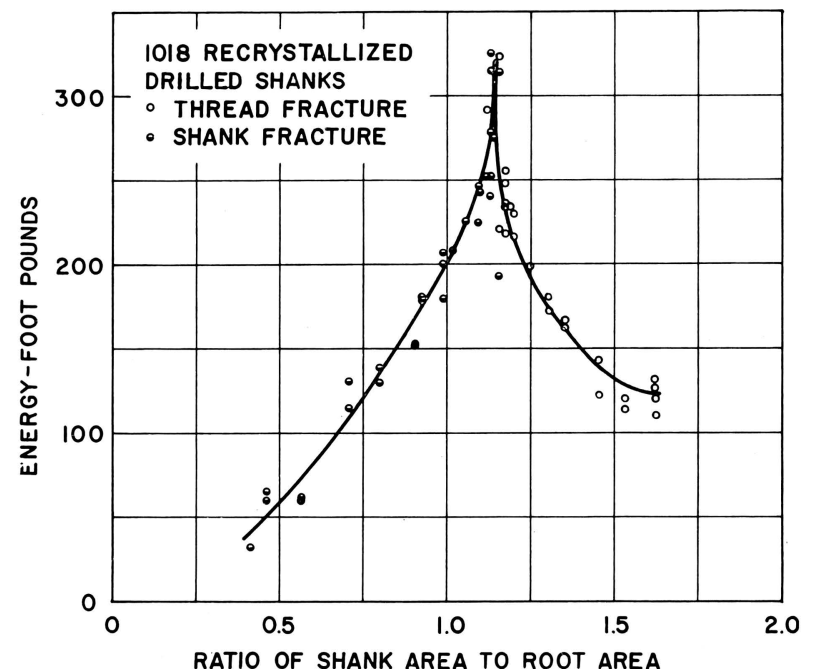

Fig. 8 Effect of Reducing Shank Area by Drilling, 1018 3/8-In. UNC Strain-ReCrystallized Bolts

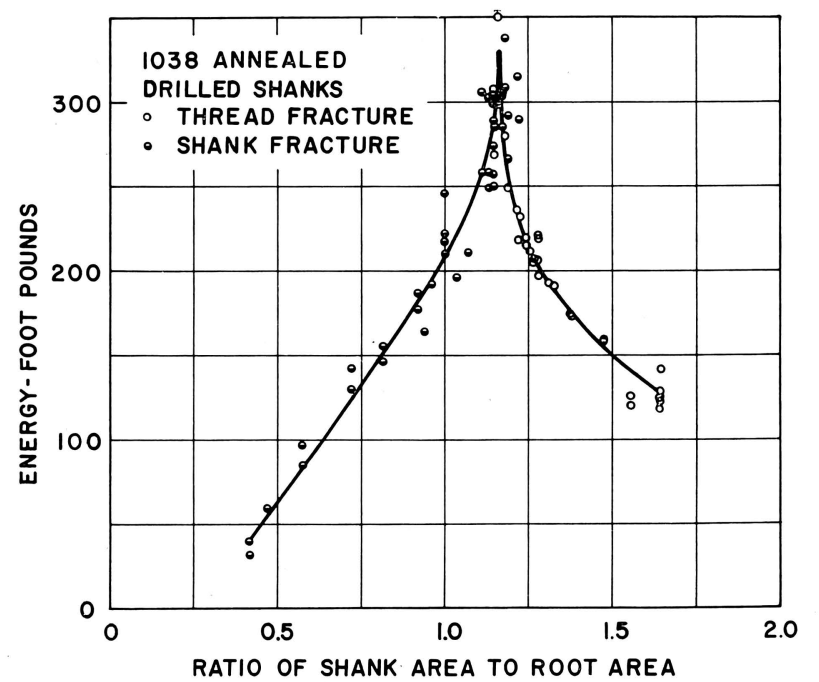

Fig. 9 Effect of Reducing Shank Area by Drilling, 1038 3/8-In. UNC AnNealed Bolts 
shank and threaded section of equal strength. The optimum shank-area to stress-area ratios of some of the bolts were only very slightly less than unity; the remainder were above unity. The stress area is a reasonably accurate measure of the static strength of the threads; therefore there was no evidence of a reduction in ultimate strength under impact due to stress concentration in the threads.

It is not surprising that the optimum shank areas for the 1038 quenched-and-tempered bolts should depend upon the method used in reducing the shank. In a drilled bolt the load is carried by the outer layers of the original shank material; in a turned bolt the load is carried by the core of the original shank. Core properties could differ from case properties for many reasons, such as, segregation, decarburization, shallow hardening, workhardened layers, plating, scale, etc. Metallographic examination of sample heat-treated bolts revealed uniform cross sections except for slight decarburization extending the width of several grains near the surface and a thin layer of surface scale. It is believed that the different optimum shank areas for drilled bolts and turned bolts may be attributed to the effect of this scale plus the slight decarburization. This may be explained by referring to the optimum ratios grouped for comparison in Table 2 . The 1038 bolts had been quenched and tempered by the manufacturer and were covered with the normal amount of scale. (Bolts from two different manufacturers gave identical results.) Drilling the shank removed no scale, thus the original scale was included in the calculated shank and thread areas. Turning the shank removed the shank scale, thus this scale was no longer included in the calculated shank area. For equal strengths, an area including scale would of necessity be slightly larger than an area not including scale; consequently, different optimum ratios would be obtained. The same effect is in evidence for the 1038 bolts of Table 2 which were annealed. During annealing, the surfaces of previously drilled holes were oxidized, resulting in a slight loss of effective cross section. Consequently, the optimum ratio of the bolts drilled before annealing was higher than that of the bolts drilled after annealing.

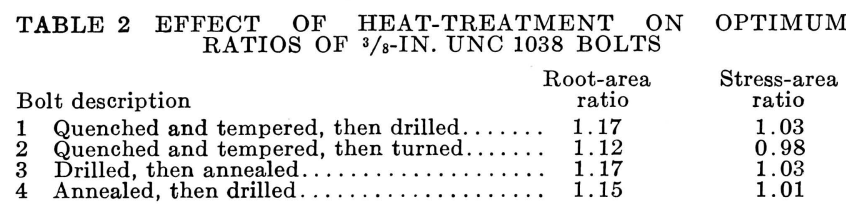

The higher optimum ratios obtained for the 1018 cold-forged bolts indicated that the threaded sections of these bolts were unusually strong in comparison with their shanks. This was undoubtedly due to work hardening of the threaded section during the thread-rolling operation. As shown in Table 3 and Figs. 4 and 8 , a strain-recrystallization heat-treatment removed this effect, lowering the optimum ratio from 1.23 to 1.15 . A full anneal had little additional effect, except that the more severe surface oxidation resulted in a higher optimum ratio when the bolts were drilled before heat-treatment rather than after. Referring to Table 1, it will be noticed that the optimum ratios for the $5 / 16$ and $7 / 16$-in. cold-forged bolts were higher than the ratio for the $3 / 8$-in. cold-forged bolts. Although the smaller $5 / 16$-in. thread received somewhat less

TABLE 3 EFFECT OF HEAT-TREATMENT ON OPTIMUM

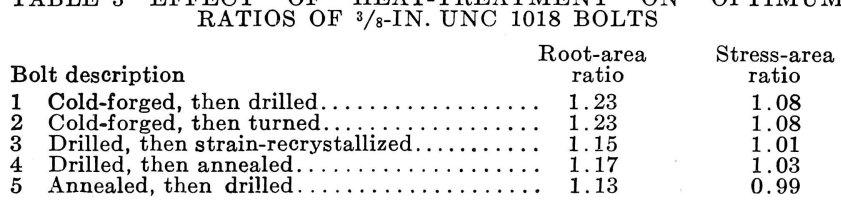

plastic deformation during thread rolling, the work-hardened region occupied a larger fraction of the total cross section than in the case of the $3 / 8$-in. bolts, resulting in a higher optimum ratio. The larger $7 / 16^{-i n}$. threads received more plastic deformation during thread rolling than the $3 / 8$-in. threads, resulting in increased strength and a higher optimum ratio. Thus the optimum shank areas for cold-forged bolts in general would depend on the amount of plastic deformation required to form the threads, the percentage of total cross section occupied by the cold-worked region, and the work-hardening characteristics of the material. Although the transition from thread fracture to shank fracture for the cold-forged bolts occurred near the optimum ratio, inspection of Figs. 4 and 5 will reveal that maximum energy was absorbed when shank fracture rather than thread fracture occurred, since the work-hardened threads were more brittle than the shank.

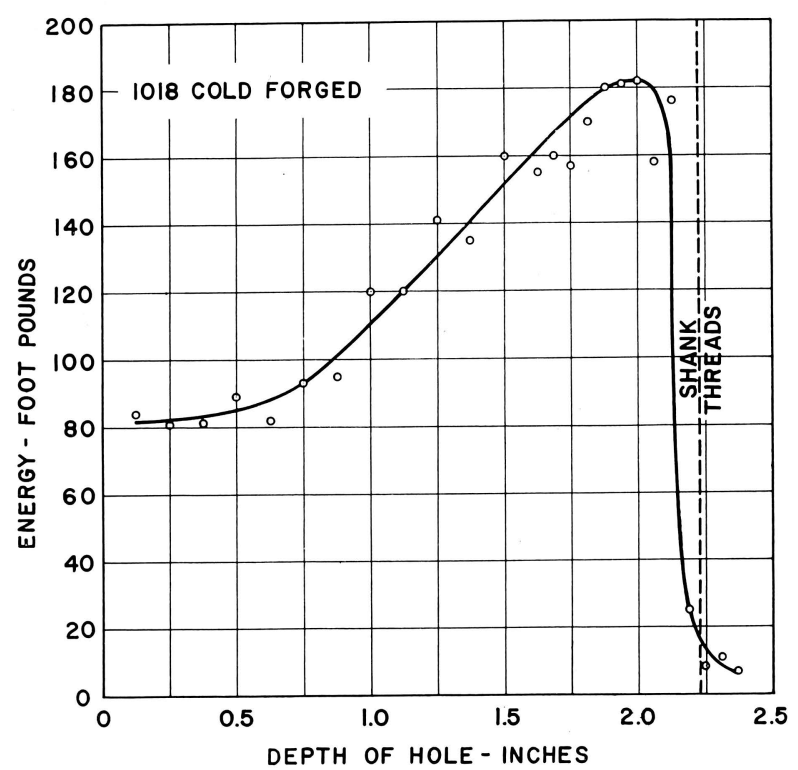

Fig. 10 Effect of Length of Reduced Section of Shank, 1018 3/8-In. UNC Cold-Forged Bolts Drilled

It was anticipated that the impact strength would increase as the length of reduced section of shank increased. A series of tests was made in which the depth of drilled hole and length of turned section were varied. Fig. 10 shows typical results for $3 / 8$-in. cold-forged bolts drilled for optimum shank areas. For shanks reduced by drilling, the bottom of the hole should not approach too close to the threaded section; otherwise the hole will weaken the cross section near the first thread. For the sizes tested, a safe distance to maintain between the bottom of the hole and the first thread was $1 / 4$ in. The exposed length of threaded section between the nut and bolt head serves the same purpose as the reduced shank and affects, the energy absorption in the same manner. Although longer reduced shanks or exposed threaded sections increased the energy absorption, the optimum shank areas were independent of these lengths as long as the lengths were about 1 diam or more.

The general appearance of impact fractures was similar for all of the bolt materials. Substantial elongation and necking occurred at all of the fractures. A typical impact fracture in the shank of a drilled 1018 cold-forged bolt is shown in Fig. 11(D). Fig. 12 shows several 1038 quenched and tempered bolts. Fig. $12(\mathrm{~B})$ is a typical impact thread fracture and may be compared with the static thread fracture of Fig. 12(A). Fig. 12(C) shows a typical impact fracture in a reduced shank and Fig. 12(D) shows 


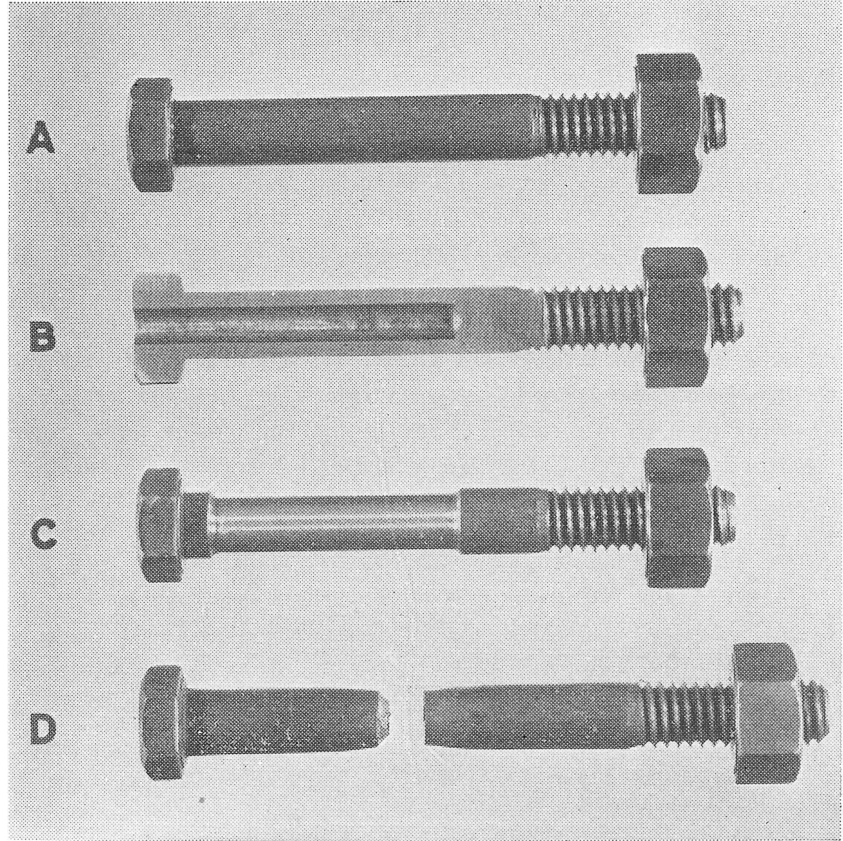

(A) Typical test bolt as purchased

(B) Sectioned bolt showing drilled hole

(C) Bolt with shank reduced by turning

(D) Typical impact fracture in shank of drilled bolt Fig. 11 Test Bolts

a bolt with an optimum shank area which elongated but did not fracture. Many bolts exhibited multiple necks. The elongation, reduction of area, and appearance of the impact fractures definitely placed them in the ductile classification. Therefore the notch sensitivity of the threads was not a factor of importance in these tests. Variations in surface finish and fillet radius of turned shanks had no effect on the impact strength, and no fractures occurred at the fillets. The transition from ductile to brittle failure would be expected only if the temperature were lowered, the striking velocity increased, or some other less important factor varied sufficiently.

Bolts have been manufactured in the past by rolling threads directly upon a shank of uniform diameter, the shank diameter being slightly greater than the pitch diameter of the resulting threads. The shank-to-root-area ratio of such bolts would be greater than any of the optimum ratios in Table 1; hence additional shank reduction would be necessary in order to obtain maximum impact strength.

The use of spring washers as a means of increasing impact strength of bolts has been frequently discussed. Certain considerations in the proper design of such spring washers are clarified by the results of this investigation. If the spring washer is to be used to its fullest capacity in absorbing energy at all loads up to actual bolt fracture, it should be proportioned to undergo plastic deformation in unison with the bolt itself. In other words the spring washer should in effect serve as an additional length of reduced bolt shank. If loaded in tension and made of the same material as the bolt, its cross-sectional area should be equal to the optimum shank area. However, a compact and practical spring washer probably would be loaded in bending, and would not necessarily be made of the same material of the bolt. In this case the proper matching of washer to bolt might be a problem requiring experimental work similar to that of determining optimum shank areas. A simple elastic resilience calculation will show that a spring washer of reasonable size stressed below

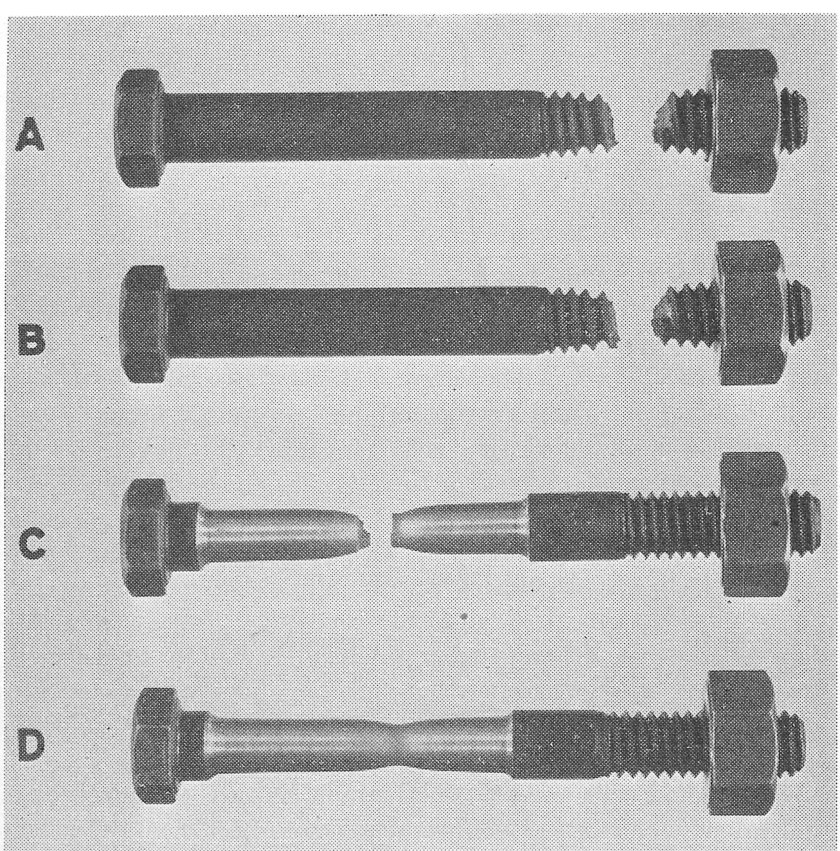

(A) Typical static thread fracture

(B) Typical impact fracture in threads of bolt with full shank

(C) Typical impact fracture of bolt with shank turned down to thread-root area

(D) Bolt with optimum shank area which did not fracture under impact

\section{Fig. 12 Quenched-AND-Tempered Bolts}

its elastic limit at loads corresponding to bolt ultimate strength would offer negligible assistance in absorbing sufficient energy to prevent bolt fracture. Such a spring washer would act only as an additional length of full-size bolt shank. On the other hand, a spring washer stressed to the same degree as a reduced shank and occupying a similar volume would absorb a comparable amount of energy.

Since it could be deduced from the results that the ultimate strength during impact was not reduced by stress concentration in the threads, there would appear to be no incentive to attempt to change the stress distribution by modification of the nut. It is possible, however, that a nut might be proportioned to do double duty by also serving as a spring washer.

Gaskets have negligible effect on the impact energy required to fracture a bolt. Although gasket rigidity may determine the extent to which the external load is transferred to the bolt at stresses below the elastic limit, the energy absorbed at these stresses is very small compared with the total fracture energy. A thick gasket may appear to increase the energy required for fracture; however, this is due to the increase in length of the exposed threaded section, which has the same effect as increasing the length of the reduced shank.

\section{Conclusions}

In summary, the room-temperature fractures of small and medium-sized steel bolts under single impact loads were of the ductile rather than brittle type; stress concentration, if present, had negligible effect in reducing the ultimate strength during impact. Substantial increases in energy required for fracture were obtained by reducing the shanks to the correct crosssectional areas. The optimum shank areas for heat-treated steel bolts were approximately 2 per cent less than the corresponding tensile-stress areas if the oxidized shank surfaces were removed by turning, or approximately 2 per cent more than the 
corresponding tensile-stress areas if the shanks were drilled and the oxidized shank surfaces retained. Because of work hardening, the optimum shank areas were higher for steel bolts with rolled threads not subsequently heat-treated, being from 8 to 11 per cent greater than the corresponding tensile-stress areas.

The utility of the foregoing information is well illustrated by the three bolts (B), (C), and (D) of Fig. 12. These bolts were subjected to identical impact loads of $255 \mathrm{ft}-\mathrm{lb}$. Bolt(B), which had a full shank, fractured in the threads. The shank of bolt (C) had been turned down to the thread-root area; this reduction was excessive, and the bolt fractured in the shank. Bolt (D) had a shank of optimum cross section, and although considerably elongated, did not fracture. This information does not assist the designer in determining the size of bolt required for a certain application. However, once the size has been determined by previously used and possibly empirical methods, the designer will be able to specify superior bolt proportions in cases where the joint must primarily absorb a given amount of energy. Experience gained as a result of using such bolt proportions in service should eventually lead in many cases to revised procedures for selecting bolt sizes and to greater economy in design.

\section{BIBLIOGRAPHY}

1 “Die Vorzüge der Dehnschraube," by A. Thum and F. Debus, Zeitschrift des Vereines deutscher Ingenieure, vol. 79, 1935, pp. 917-919.

2 "Machine Design," by A. W. Smith and G. H. Marx, John Wiley \& Sons, Inc., New York, N. Y., fourth edition, 1915, pp. 156-158.

3 "Design of Machine Elements," by V. M. Faires, The Macmillan Company, New York, N. Y., third edition, 1955, p. 126.

4 "On the Strength of Highly Stressed Dynamically Loaded Bolts and Studs," by J. O. Almen, Journal of the Society of Automotive Engineers, vol. 52, 1944, pp.151-158.

5 "Effect of Screw Threads on Fatigue," by S. M. Arnold, Mechanical Engineering, vol. 65, 1943, pp. 497-505.

6 "Fundamentals of Brittle Behavior in Metals," by E. Orowan, Symposium on Fatigue and Fracture of Metals, The Technology Press, Massachusetts Institute of Technology, Cambridge, Mass., 1952, pp. 139-167.

7 "The Velocity Aspect of Tension-Impact Testing," by W. H. Hoppman, Proceedings of the American Society for Testing Materials, vol. 47,1947, pp. 533-543.

8 "Measurement of Dynamic Stress and Strain in Tensile Test Specimens," by R. O. Fehr and E. R. Parker, Proceedings of the Society for Experimental Stress Analysis, vol. 1, no. 1, 1943, pp. 76-82.

9 "Impact and Static Tensile Properties of Bolts," by H. L. Whittemore, G. W. Nusbaum, and E. O. Seaquist, Journal of Research, National Bureau of Standards, vol. 14, 1935, pp. 139-188.

10 "Strength of Screw Threads Under Tensile, Fatigue, and Impact Loads," by R. R. Moore, Product Engineering, vol. 10, 1939, pp. 475-479.

11 "Properties of Bolts Under Shock Loading," by H. M. Forkois, R. W. Conrad, and I. Vigness, Proceedings of the Society for Experimental Stress Analysis, vol. 10, no. 1, 1952, pp. 165-178.

\section{Discussion}

V. L. Doughtie. ${ }^{4}$ The authors are to be commended for their extensive tests and excellent presentation of the results. Apparently, they have considered the many factors involved in the strength of bolts. A discussion of this paper could be given in two words, well done.

As indicated by the title, the purpose of the experiments was to determine the proper shank area of a bolt for impact loads; but other factors affecting the strength of a bolt were determined and discussed. Nut thickness, tightening torque, length of reduced area, heat-treating, use of spring washers, notch sensitivity, surface finish and fillet radius of the turned-down shank, nut modification, and gasket thickness are some of the factors con-

\footnotetext{
${ }^{4}$ Professor, Department of Mechanical Engineering, University of Texas, Austin, Texas. Fellow ASME.
}

sidered. The tests show that the ratio of the shank area to the root area should be slightly above unity instead of unity or below as previously considered to be good practice. It is also clearly brought out that bolt size, material, and heat-treatment influence this ratio.

It should be observed that in most cases, the ratio of the shank area to the stress area is about unity. The Unified Thread Standards give values of the stress area and not root areas. Would it not be desirable to discontinue the use of root area?

The authors state: "In fatigue, the reduced shank may relieve stress concentration at the last thread." Perhaps, it is a question of definition of the last thread. The first threads in a nut carry most of the load.

It is surprising that the scatter of the results is not greater than it is. Several years ago, the writer tested in pure tension hundreds of bolts as purchased and found a much larger variation in failure loads.

The length of the reduced shank for the curves shown was $1^{5} / 8$ in. for the drilled shank and $1 \mathrm{in}$. for the turned shank. Fig. 10 of the paper indicates that a length of hole of approximately 2 in. absorbs the maximum energy. The authors state: The optimum shank areas for maximum energy absorption were independent of the length of reduced section of shank as long as the length was at least one diameter or more. If this is interpreted correctly, why drill the holes to a length of $1 \frac{5}{8}$ in.? Also, were tests run to determine the effect of the length and location of the turned-down section on the energy absorbed? Is it likely that the drilled hole in the bolt head for the 1038 steel had an effect on the rigidity of the head causing different ratios?

The writer does not follow the authors' reasoning for the $3 / 8^{-}$ in. UNC 1018 cold-forged bolts having a smaller optimum ratio than the $5 / 16$-in. UNC and $7 / 16$-in. UNC bolts of the same material. It seems that if this reasoning were correct the ratio would decrease with an increase in bolt size. It is hoped that the authors will extend their research to cover larger-sized bolts.

W. C. Stewart. ${ }^{5}$ The authors present some very new, interesting, and useful information with respect to the design of bolts. Of particular interest is the conclusion that the proper shank area of the bolt for maximum energy absorption (quenched and tempered bolts) is close to the so-called "tensile stress area." This area, in recent years, has become adopted as the conventional area for computing tensile strength of threaded sections since it is more representative than the root area. The present impact tests tend to confirm this assumption.

It would have been helpful if the authors had added another series of tests comparing optimum reduced-shank bolts with bolts threaded to the head (no shank, or only a very short shoulder). Presumably, the threaded-to-head bolts would also give optimum energy absorption. If this assumption proved true, it would have a practical significance since threaded-to-head bolts could be manufactured more economically than waisted or drilled bolts.

The authors observed that bolts tightened beyond their elastic limit suffer a loss of energy absorption. From this it might be concluded that it is bad practice to tighten the bolt above its elastic limit. Experience, however, indicates that this is not bad practice and there are other good reasons for so tightening in many applications. The authors' observations are no doubt true for the test arrangement used. The bolts were stretched almost to the breaking point and could stand very little further deformation (energy absorption). In this test setup all of the energy input to the joint was forced into the bolt. Therefore the bolt fails with little energy absorption. In an actual joint this situation generally does not hold.

${ }_{5}$ Technical Adviser, Industrial Fasteners Institute, Cleveland, Ohio. Mem. ASME. 
In practice the energy input can be absorbed either by the bolt or by the structure or by both. The bolt alone is not forced to absorb all of the energy. In such a joint the bolt may not break even though large amounts of energy are supplied, the energy being absorbed by the surrounding material. In other words, the high bolt tension deflects the energy and forces the structure to take the impact. The structure should be designed to take this energy anyway, unless the bolt is looked upon as a "safety valve" protecting an underdesigned fragile structure.

\section{Authors' Closure}

The authors wish to thank Professor Doughtie and Mr. Stewart for their interest in the paper and their valuable comments.

Although the results presented in the paper do emphasize the usefulness of the stress area in bolt strength calculations, it should be noted that cold-forged bolts present a somewhat exceptional case. These bolts were stronger than their stress areas would indicate, since their optimum shank areas were substantially greater than the corresponding stress areas. The increase in strength was undoubtedly due to work hardening during thread rolling, and the magnitude of the increase would depend upon such factors as bolt material, amount of plastic deformation required to form the thread, depth of the workhardened layer, and previous work hardening due to the operation of reducing the diameter of the threaded section prior to thread rolling. In view of the many variables involved, it is not surprising that different optimum ratios were obtained for different sizes of cold-forged bolts. Furthermore, it will be difficult to accurately predict either the optimum shank areas or strengths of cold-forged bolts in general unless specific test data are available.

Both the area and the length of the reduced shank had an effect upon the energy absorption of a given bolt. For constant length of reduced shank, maximum energy absorption was obtained with a certain critical or optimum shank area. For constant shank area, the energy absorbed during fracture increased as the length of reduced shank increased. The optimum shank area for a given material condition remained constant regardless of the length of reduced shank. However, the above relationship was not investigated thoroughly for extremely short lengths of reduced shank, since little gain in energy absorption would be realized by such modification. Consequently, it was stated in the paper that the optimum ratios presented should be considered to apply only to reduced shank lengths of approxi- mately one nominal bolt diameter or more. It should also be stated that some variation in the optimum ratios might result if the thickness of clamped parts were reduced until almost no threads were exposed under the nut.

The length of exposed threaded section between the nut and the bolt head acted in effect as an additional length of reduced shank, and energy absorption was increased by increasing the length of exposed threads. It would therefore seem reasonable to conclude that a bolt threaded to the head would offer maximum or near maximum energy absorption. However, cold-forged bolts might prove to be an important exception. Inspection of Figs. 4 and 5 shows that maximum energy was absorbed by coldforged bolts with optimum shank areas when shank fracture rather than thread fracture occurred, since the shanks were less brittle than the work-hardened threads. A fracture occurring in a cold-forged bolt threaded to the head would of necessity be located in the threads, with a consequent loss in energy absorption. Thus the ideal cold-forged bolt for shock loading should have a minimum length of threaded section and a maximum length of smooth reduced shank. Furthermore, the shank area should be slightly less than the optimum area in order to guarantee that energy absorption will be concentrated in the ductile shank.

It was pointed out in the paper that one advantage of a reduced shank under repeated loading may be a reduction in stress concentration at the last thread. The term "last thread" was intended to specify the location at the juncture between the shank and the threads. Other likely locations for fatigue fracture would be the juncture between the shank and the head, and the thread adjacent to the face of the nut.

The authors agree that the observed decrease in fracture energy at initial tightening stresses above the elastic limit should not necessarily be interpreted as indicating that such high tightening stresses are always detrimental. Tightening a bolt above the elastic limit produces plastic deformation and work hardening, with resulting increase in elastic limit and decrease in ductility. Because of the increased elastic limit, the ability of the bolt to absorb energy at stresses below the elastic limit would thus actually be improved by high tightening stresses. No doubt in the majority of applications a properly selected bolt would not be stressed above the elastic limit by the external load; also, the surrounding structure would normally absorb a large fraction of the energy of a shock load. However, the decreased ductility of the bolt due to high tightening stresses would be cause for consideration if large and unpredictable overloads were anticipated in structures designed with low factors of safety. 


\section{PUBLICATIONS OF THE ENGINEERING REPRINT SERIES}

Copies of the complete list of publications may be secured from the Director of the Engineering Experiment Station, University of Missouri

Reprint No.

13. The Design of Sampled-Data Feedback Systems by Gladwyn V. Lago, Associate Professor of Electrical Engineering and John G. Truxal, Polytechnic Institute of Brooklyn. Reprinted from Transactions of the A.I.E.E., Vol. 73, Part 2, p. 247, 1954.

14. Selection of Personnel by George W. Elliott, Assistant Professor of Mechanical Engineering. Reprinted from the 1954 Transcript of the Midwest Feed Production School.

15. Lightweight Aggregates for Structural Concrete by Adrain Pauw, Associate Professor of Civil Engineering. Reprinted from the Proceedings of the A.S.C.E., Vol. 81, Separate No. 584, January 1955.

16. Coating Thickness Measurements Using Pulsed Eddy Currents by Donald L. Waidelich, Associate Director, Engineering Experiment Station. Reprinted from the Proceedings of the National Electronics Conference, Vol. 10, February 1955.

17. Additions to Sample-Data Theory by G. V. Lago, Associate Professor of Electrical Engineering. Reprinted from the Proceedings of the National Electronics Conference, Vol. 10, February 1955.

18. Additions to Z-Transformation Theory for Sample-Data Systems by Gladwyn V. Lago, Associate Professor of Electrical Engineering. Reprinted from Transactions of the American Institute of Electrical Engineers, Vol. 74, January, 1955.

19. Tension Control for High Strength Structural Bolts by Adrian Pauw, Professor of Civil Engineering and Leonard L. Howard, Lakeland Engineering Associates, Inc., with a discussion on the Turn-of-the-Nut Method by E. J. Ruble, Association of American Railroads. Reprinted from the Proceedings of the American Institute of Steel Construction, National Engineering Conference, April 18-19, 1955.

20. Autotransformer Betters Motor Phase Conversion by Joseph C. Hogan, Associate Professor of Electrical Engineering. Reprinted from Electrical World, Vol. 144, p. 120, October 17, 1955.

21. Sequence Summation Factors by Adrain Pauw, Professor of Civil Engineering. Reprinted from the Proceedings of the American Society of Civil Engineers. Vol. 81, Paper No. 763, August, 1955.

22. Pulsed Eddy Currents Gage Plating Thickness by Donald L. Waidelich, Associate Director, Engineering Experiment Station. Reprinted from Electronics, Vol. 28, p. 146, November, 1955.

23. Relay Protection for Lines Being Sleet-Melted by the Short-Circuit Method by J. C. Hogan, Associate Professor of Electrical Engineering and C. G. Pebler, Commonwealth Associates, Inc. Reprinted from Transactions of the American Institute of Electrical Engineers, Vol. 74, December, 1955.

24. Supplemental Irrigation.... Careful Planning is Essential by Harry Rubey, Professor of Civil Engineering. Reprinted from What's New in Crops and Soils, Vol. 7, August-September, 1955.

25. Analysis of Single-Phase-to-Three-Phase Static Phase Converters by J. C. Hogan, Associate Professor of Electrical Engineering. Reprinted from Transactions of the American Institute of Electrical Engineers, Vol. 74, p. 403, January, 1956.

26. Enrollment and Incomes in Civil Engineering can be Increased by Harry Rubey, Professor of Civil Engineering. Reprinted from Journal of Engineering Education, Vol. 46, p. 236, November, 1955.

27. A Synthesis Procedure for Sampled-Data Systems by G. V. Lago, Associate Professor of Electrical Engineering. Reprinted from Proceedings of the National Electronics Conference, Vol. 11, p. 251, 1955.

28. Design of Optimum Phase-Shift Oscillators by Donald L. Waidelich, Associate Director, Engineering Experiment Station. Reprinted from Proceedings of the National Electronics Conference, Vol. 11, p. 222, 1955. This article also appeared in Electronics Equipment, Vol. 4, p. 38, April, 1956.

29. Investigation Concerning Polarization in Barium Titanate Ceramics by G. W. Marks, U. S. Navy Electronics Laboratory, Donald L. Waidelich, Associate Director Engineering Experiment Station, University of Missouri and L. A. Monson, U. S. Navy Electronics Laboratory. Reprinted from Transactions of the American Institute of Electrical Engineers, Vol. 75, Part I, p 469, 1956.

30. The Influence of Shank Area on the Tensile Impact Strength of Bolts by John Love, Jr., General Electric Company and O. A. Pringle, Associate Professor of Mechanical Engineering. Reprinted from Transactions of the American Society of Mechanical Engineers, Vol. 78, p 1489, October, 1956.

*Out of Print. 

University of Missouri Libraries

University of Missouri

MU Engineering Experiment Station Series

Local Identifier

LoveJr1956

Capture information

Date captured 2018 June

Scanner manufacturer Ricoh

Scanner model

MP C4503

Scanning software

optical resolution

Color settings

File types

$600 \mathrm{dpi}$

Grayscale, 8 bit; Color 24 bit Tiff

Source information

Format

Content type

Notes
Book

Text

Digitized duplicate copy not retained in collection.

Derivatives - Access copy

Compression

Editing software

Resolution

Color

File types

Notes

\section{LZW}

Adobe Photoshop

600 dpi

Grayscale, 8 bit; Color, 24 bit

Tiffs converted to pdf

Greyscale pages cropped and canvassed. Noise removed from background and text darkened.

Color pages cropped. 